\title{
EDUCATION AND THE UNDER-DEVELOPED TERRITORIES
}

\begin{abstract}
GIR SYDNEY CAINE'S paper, "Education for $\checkmark$ Development", read on September 9 before Section L (Education) at the British Association meeting in Dublin, was in the vein of Prof. P. M. S. Blackett's presidential address. Although, like Prof. Blackett, Sir Sydney was concerned largely with the under-developed countries, much of what he said about the part which education has to play in the business of development bore closely on economic or industrial development anywhere, whether in the developed or the under-developed countries. As Sir Sydney pointed out, the real difference between such countries lies in the magnitude of current incomes and current capital equipment. Broadly, the underdeveloped countries are the poorer countries of the world and the developed are the richer, and though there may be no precisely agreed definition as to the meaning of richer or poorer, there is rarely uncertainty as to the category to which particular countries belong.
\end{abstract}

If, further, we remember that at the bottom of the process of development is the creation of wealth, and that this in turn depends on the application to a country's basic national resources of human skills and labour, assisted by capital, in turn the product of human effort, it is understandable how largely education is the common factor and the common problem. Without human skill and labour, natural resources are indeed useless, and of capital Sir Sydney remarked again that it depends on human endeavour and human abstinence to bring it into existence. The spread of knowledge and skill is fundamental to the whole creation of wealth.

Sir Sydney passed briefly over the question of technical knowledge, without deprecating it, emphasizing that merely technical knowledge is by no means enough. It must be supported by advancing fundamental scientific knowledge, as well as by the habit of mind, apt to be overlooked in the West, which accepts and applies technology, combining theoretical knowledge from books and laboratory experiments with the readiness to engage in hard and dirty labour. Again, the technologist needs also the support of more general education in two senses. Besides the creation of more wealth, full and healthy social and economic development involves raising the level of social organization and economic capacity, and this can only follow as the level of education is raised. Secondly, economic developments do not occur in isolation; and the production of more wealth brings new problems of distribution and utilization, the solution of which requires men and women trained in economics and social science as well as in natural science and technology.

Often, however, the problem of economic improvement is fundamentally one of sociology, not technology. The would-be developer repeatedly encounters situations in which sociological obstacles prevent the adoption of a major technological change which would substantially improve economic output, and Sir Sydney cited as an example the production of rice in Ceylon. This could be increased substantially by major new technical developments of irrigation and opening up unused land, but much more substantially by the adoption by existing rice cultivators of better methods already proved else. where. The latter means would not have involved the considerable capital investment necessary for irrigation and land development, but propaganda and persuasion of a complex type, because the existing technique of growing rice is bound up with the whole way of life in villages, and affects family relations, inheritance and even religion, thus representing a long task for the sociologist as much as for the agricultural technician.

This illustrates the second broad aspect of the need for general education which Sir Sydney Caine emphasized. It is not sufficient for the directors or operators of development to be trained in matters other than technology : the general public with whom they deal also must be sufficiently well and broadly educated. In agriculture, as in all industrial or other advanced technological operations, a sufficient level of general education is essential ; and in most underdeveloped countries the shortage of technicians and skilled craftsmen is the real obstacle to rapid economic development. Technology is not enough. Technicians and technologists must be educated in the social as well as in the natural sciences, and the mass of the population as well as the technical élite require general education.

Reviewing next the problems of education in the under-developed countries, Sir Sydney pointed out that only highly developed countries can afford general education in its modern form, and in starting from scratch in the under-developed countries the cost of technical education can be appalling. Moreover, the diversity of language constitutes a complication which can be a most serious obstacle, particularly as higher education is bound to make great use of languages foreign to the mass of the people, while mass education is necessarily condueted in the vernacular. The supply of text-books and periodicals is another great difficulty, especially at the university and postgraduate level ; and the whole problem is often further aggravated by the emotional aspects of language. Sir Sydney did not hesitate to condemn the waste of time and effort, at a time when rapid progress in education is so urgent, caused by the multi-lingual education due to racial or national prejudice. Even without this, it is difficult, indeed, with the great shortage of highly trained men and women, to induce enough of them to enter the higher levels of the teaching profession, and especially in those countries emerging to national status from Colonial dependence.

All this raises serious threats to the quality of education. In spite of the acute shortage of qualifiod local citizens for university or technical teaching, for example, emotionalism sometimes prevents effective use being made of outside assistance. Sometimes, too, it is assumed that if the right things are done, real incomes will rise and real wealth grow unprecedentedly quickly; and there is real danger of sacrificing quality to quantity and of so overloading the teachers that they become ineffective. Sir Sydney referred particularly to the danger of lowering standards of admission to universities. According to 
a recent report from the University of Indonesia, of the 2,000 registered students in the Faculty of Engineering for the year in question, 1,300 were in the first year, a dozen or so in the fifth or final year and only one graduated.

The considerations noted by Sir Sydney imply that by its very nature the task of education for development must fall in the main upon the under-developed countries themselves, and in this connexion he stressed the importanee of the 30,000 overseas students in the United Kingdom, the great majority of whom come from under-developed countries, while a high proportion of these are privately financed. Nevertheless, the developed countries have a most important part to play, particularly at the level of university and technical training, but their own specialized man-power difficulties set strict limits to what they can do ; and Sir Sydney commented that the London School of Economics has every year to reject a high percentage of applications from abroad for higher degree studies because it, has reached the limit of the numbers which its teaching staff can effectively supervise. The resources to be shared with the less advanced countries are not solely finances but above all highly trained men and women; and this is already being done by numerous agencies. Besides the great help given by British universities, through their organization as well as by offering places to overseas students, more than $£ 29$ million has been contributed during the decade 1946-56 by the British taxpayer to overseas students and education through the British Council and Colonial Development and Welfaro Funds.

As the fruit of these and earlier efforts, there are now in British Colonies or former Colonial dependencies four universities, five university colleges and various other institutes of higher education. The Colombo Plan, which is essentially a collective name for various loosely co-ordinated pieces of mutual assistance by one Commonwealth country to another, has brought to numerous individuals in the underdeveloped areas opportunities of study overseas and grants of assistance to educational institutions. Commonwealth countries are also helping in ways quite outside the Colombo Plan, while many countries have received considerable aid to education under American foreign aid programmes. There is also the substantial help given by the Rockefeller Foundation and other private foundations, particularly for the initiation of new projects; and on the international plane much is being done through the Technical Assistance Board of the United Nations, through the United Nations Educational, Scientific and Cultural Organization and in specifically technical fields by the other specialized agencies such as the Food and Agriculture Organization and the World Health Organization.

Both the finance and technical personnel required for all this come in the main from the developed countries, and in this connexion Sir Sydney urged the importance of doing everything possible to ensure that British people who undertake a period of service abroad do not thereby damage their prospects for appointments in Britain. Something more could also be done to encourage the exchange of books and periodicals and the movements of scientists and other learned men. This is still liable to be hindered by political considerations even in non-Communist countries, and Sir Sydney fears that there is a danger of a system of exclusion of books and periodicals arising in non-Communist under-developed areas. Every effort should be made to assist people from under developed countries to attend meetings of learned societies and to ensure that the problems of these countries receive attention at such meetings; Sir Sydney also suggested that the production in a single language appropriate to a particular area of summaries of scientific publications in diverse languages would be a very fruitful piece of international co-operation.

Such projects can scarcely become effectivo, however, unless the less-developed countries refrain from accentuating difficulties by exaggerating political, linguistic and psychological obstacles. If, however, the developed countries use to the full their opportunities for initiative in sharing their educational resources along such lines as Sir Sydney Caine indicates, that in itself would encourage the growth of mutual tolerance and goodwill. There would, nevortheless, appear to be a wide field in which professional societies could support what the universities and many educational institutions are already doing, not only to encourage the growth of such an atmosphere of goodwill, but also, and no less important, to assist the wisest and most effective use of the most precious of all resources, in developed and under-developed countries alike that of trained men and women.

\section{BIOLOGICAL RHYTHMS}

$A^{\mathrm{T}}$ if the sixth conference of the Society for Biological Rhythms, held on the Semmering, near. Vienna, during August 26-28, thirty-six papers were presented by members and guests from eleven countries. They were welcomed by Dr. E. Dissmann (Klagenfurt), the local secretary.

The main theme of the opening session organized by Prof. A. Jores (Hamburg) was "Time in Biology", which was covered by six invited speakers. $H$. Laurell (Halmsted) critically discussed ancient and modern ideas of time, and contrasted its physical, physiological and psychological aspects; he also reviewed methods of measuring time. J. Aschoff (Heidelberg) elaborated the idea of time-eues or clues (Zeitgeber), namely, those periodical factors, external to a rhythmic system, which can be shown experimentally to control its phase. He demonstrated that in constant conditions of temperature and illumination and in the absence of noise or mechanical disturbance, $24 . \mathrm{hr}$. patterns in the motor activity of vertebrates persist but gradually fall out of step, thus indicating that all external time-cues have been successfully eliminated. By reintroducing these potential cues one at a time their relative efficacy can be assessed. H. Kalmus (University College, London) observed that all life is accompanied by an incessant redistribution of material in space and time, and thus defined the investigation of biological rhythms as a study of the synchronization of mechanisms of transport. The appearance of any biological material at the 'right' time and at the 'right' site can be interpreted as a homoostatic: arrangement brought about by the remote causes of selection, but must also be explained by the operation of physiological cues at any particular time. The opportunist nature of selection and the complexities of biological organization frequently produce nonoptimal time adaptrations and limited adaptability. 